\title{
Dislocation of the mandible
}

\section{A rare complication after gastroscopy}

Q. Mangi, P. F. Ridgway, Z. Ibrahim, D. Evoy

Department of Surgery, Wexford General Hospital, Wexford, Ireland

[Surg Endosc (2004) 18: 554, DOI: 10.1007/s00464-003-4223-z]

P. F. Ridgway's name was spelled incorrectly in this article and is corrected here. 